\title{
Carbohydrates for Diabetes?
}

\author{
Ala Akram Zaidan* \\ Nutrition and Dietetics, Real Health Center, UAE \\ *Corresponding author: Nutrition and Dietetics, Real Health Center, UAE
}

\section{Opinion}

Would you like a piece of bakes potatoes? N0000, I am Diabetic. An answer that we usually face with people with Diabetes Type Two. And mostly whenever we ask them who told you that you are not allowed to eat carbohydrates, the answer is our Endocrinologist! As Clinical Dietitian, I am facing this case on daily basis average. Now, let me tell you that this is not the way. Diabetes type two diets should contain $45-50 \%$ of Carbohydrates Does this mean that $50 \%$ of my food can be from chocolates and candies? Neither this is the case. Another question to be added: Does this diet help with Obesity? The answer is YES! There are a lot of weight loss diets that are rounding in the field these days. As per my experience, the Diabetes Diet is the only diet that help in weight loss and in the same time to be continued as a healthy lifestyle. (NOTE: in case no other health complications and other Therapeutic diets to be followed).

For a $2000 \mathrm{kcal}$ daily intake, this balanced diet consists of

a) Carbohydrates (45-50\%): an average of 8 servings of Carbohydrates per day coming from whole grains, 4 servings of fruits , 6 servings of vegetables and 2 servings of low-fat milk. These foods are good source of vitamins, minerals, dietary fibers and energy.

b) Proteins (10-20\%): an average of 8 servings of Meat of which $80 \%$ coming from Lean protein like cottage cheese, skinless chicken) and plant-based sources like legumes (noting that legumes have carbohydrates along with proteins to be counted and managed).

c) Fats $(25-35 \%)$ : these fats on average of 5 servings where trans-fat (like margarines and spreadable ) should be eliminated and saturated fats to be less than 7\% (like chicken skin) and the best sources to come from raw olive oil , nuts and fish to be taken three times per week to get the needed Omega

d) Alcohol: one to two drinks per day, 15 to $30 \mathrm{~g}$ of alcohol are associated with decreased risk of coronary heart disease. However, these to be considered an addition to the regular food and manage Carbohydrates servings instead.

So, having Breakfast, Lunch, Dinner and two snacks between the three meals will help to keep a balanced diet and full throughout the day with adequate amounts of liquids to stay hydrated. Now, how can I manage Obesity with this diet? Starting with the Total Energy Expenditure, we start by reducing the Energy Intake by 500 kcal per day. As a result, losing 2.2 pounds per week or 9 pounds per month as an average. Although usually as start of this diet and changing the lifestyle into healthier one and quitting bad habits, we see more weight loss in less time. Along with time, and when weight loss takes place, the Energy Expenditure of the body decreases. And the body gets accustomed to the amount of Energy Intake. In this case, we continue the Energy Intake reduction, so the weight loss continues! Adding physical activity is a big benefit that will help in weight loss and later body weight maintenance. When Diabetes type two can be managed by Diet, why to suffer from its short- or long-term complications? Why to take medications and suffer their side effects when you can manage it by healthy lifestyle! Stay Healthy and Happier.

NOTE: Diet is always customized as per every person's case. 
(c) (i) This work is licensed under Creative

To Submit Your Article Click Here:

Submit Article

DOI: 10.32474/ADO.2020.02.000144

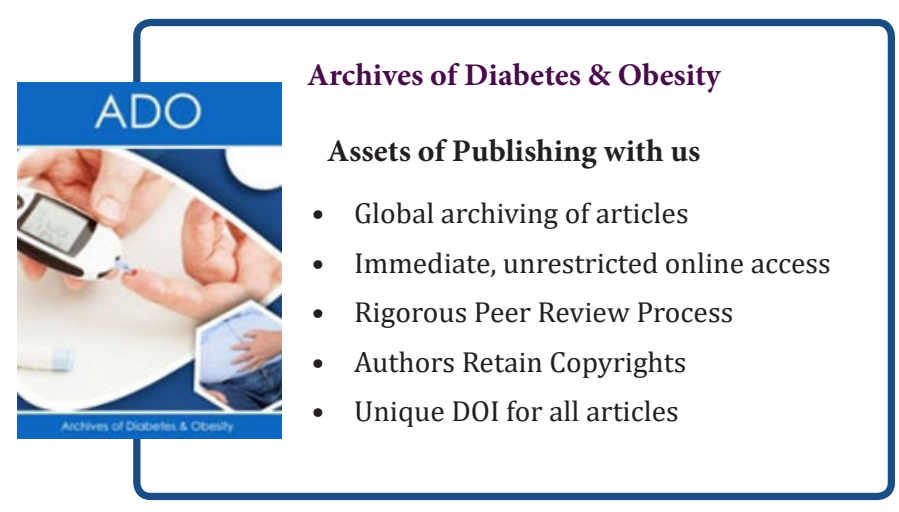

